\title{
Ocular morbidity among children of Baglung, Nepal
}

\section{Sharma D' iD $\triangle$, Rajak $A^{2}$ iD, Shrestha S $\mathrm{S}^{3}$ iD}

'Dikchhya Sharma, Lecturer; ${ }^{2}$ Ashik Rajak, MBBS Graduate; ${ }^{3}$ Sabina Shrestha, Professor, Department of Ophthalmology, Kathmandu Medical College Teaching Hospital, Kathmandu, Nepal.

\begin{abstract}
Background: Development of the visual system occurs during childhood is completed by eight years of life. Ocular disorders occurring during this period can lead to visual impairment which can have a lifelong impact on the life of the child. Early detection and treatment of ocular problems among children minimises the risk of visual impairment and amblyopia.

Objectives: This study aimed to determine the pattern of ocular morbidity among children attending the health camp in Baglung.

Methodology: This was a descriptive cross-sectional study conducted to determine the pattern of ocular morbidity among children in the western region of Nepal, Baglung district. The study was conducted in the month of December 2019 for two days after receiving ethical approval. All data obtained were analysed according to age, sex and pattern of ocular morbidity and were expressed in frequency, percentage and mean as applicable. Convenience sampling technique was used.

Results: Five hundred and thirty two children were evaluated in the study. Among them, 143 (26.87\%) had ocular morbidity. The mean age of children with ocular morbidity was 9.6 \pm 5.4 years. The total male to female ratio was $1.18: 1$ and that amongst those with ocular morbidities was seen to be $2.04: 1.1$. The most common ocular morbidity was refractive error in 43(8.08\%) followed by conjunctival in 32 (6.01\%) and lid disorders in 29(5.45\%) respectively.

Conclusion: Most of the morbidities observed were either preventable or treatable, therefore, eye health camp is an effective method to identify them.
\end{abstract}

Key words: Children; Eye diseases; Morbidity; Vision.

\section{INTRODUCTION}

$\mathrm{O}$ cular diseases create a great burden among the morbidities affecting children. Initial years of life of a child are most important ${ }^{1}$. Any child with ocular

\section{Access this article online}

Website: www.jkmc.com.np

DOI: https://doi.org/10.3126/jkmc.v9i2.35529

\section{HOW TO CITE}

Sharma D, Rajak A, Shrestha S. Ocular morbidity among children of Baglung, Nepal. J Kathmandu Med Coll. 2020;9(2):92-5.

Address for correspondence

Dr. Dikchhya Sharma

Lecturer, Department of Ophthalmology

Kathmandu Medical College Teaching Hospital

P.O. Box number: 21266

Sinamangal, Kathmandu, Nepal

E-mail: dixya_543@hotmail.com

Copyright @ 2020 Journal of Kathmandu Medical College (JKMC)

ISSN: 2019-1785 (Print), 2091-1793 (Online)

(i) (S) This work is licensed under a Creative Commons Attribution-Non Commercial 4.0 International License. disorder has a major impact on the social, psychological, and professional development during their transition to adulthood'. According to the World Health Organisation, there are an estimated 1.4 million childhood blindness worldwide of which two third live in six developing countries including $\mathrm{Nepal}^{2}$. Childhood blindness is a significant component of WHO vision 2020 program $^{3}$. Also in 1997; the Pediatric Eye Disease Investigator Group (PEDIG) was formed to conduct clinical research in eye disorders that affect children like amblyopia, strabismus etc. PEDIG was formed to fill a void that existed in clinical research in pediatric ophthalmology $y^{4}$.

Ocular problems in children are unique and different from adults not only due to their problem in articulation but also because of the potential to develop amblyopia ${ }^{5}$. This is mainly important because some eye conditions may only cause ocular morbidity while others may lead to blindness. The majority of blindness is either potentially curable or preventable. Through eye health camps, children can be screened for diseases such as refractive error, strabismus, amblyopia etc ${ }^{6}$. 
Majority of eye hospitals in Nepal are either located in the Terai region of the country or in the capital city. People and especially children living in hilly areas are devoid of the best eye health care facilities. These types of eye health programs will help in determining the magnitude of ocular morbidity and referring children in need to tertiary eye hospitals thereby reducing the burden of visual impairment and blindness. This study aims to evaluate the pattern of ocular morbidity in children of western mountainous region of Nepal, Baglung district who visited our eye health camp.

\section{METHODOLOGY}

This is a descriptive cross-sectional study conducted in the western mountainous region of Nepal, Baglung district. All children attending the two days eye camp conducted on $19^{\text {th }}$ and $20^{\text {th }}$ December 2019 at Amrit Aadarsha School in Baglung were included in the study. Approval from the Institutional Review Committee of Kathmandu Medical College Teaching Hospital was obtained before starting the study. Convenience sampling was used. It was ensured that the parents or accompanying guardians were fully informed about the study and gave consent to participate in the study.

The camp was conducted by two ophthalmologists, one ophthalmology resident, one optometrist, one ophthalmic assistant and one ophthalmic technician. History taking and clinical examination of the child was done including visual acuity, refraction, extraocular movement, Hirschberg test, cover/uncover test, convergence, anterior segment and posterior segment examination.

In children less than four years old visual acuity was measured using the fixation preference method with a torch light and were then sent for retinoscopy if needed. Children aged 4-6 years were examined using LEA symbols chart at 3 meters distance. In children aged 6 years and above, vision was assessed using the Snellen acuity chart ${ }^{7}$. Subjective refraction and cycloplegic refraction was done whenever needed. Anterior segment examination was done using the torch and handheld slit lamp (Heine, Germany). Posterior segment examination was done with direct ophthalmoscope. Dilatation was only done when the vision was not fully corrected or in case of traumatic eye injuries. All the findings were recorded in the pre-designed proforma. When there were co-existing eye diseases, a decision for the primary diagnosis was made by the senior ophthalmologist. All children attending the camp with their parents/guardian giving consent were included as the study population and those not giving consent were excluded.

Data was analyzed using the IBM Statistical Package for the Social Sciences Statistics for Windows, version 20 (IBM Corp., Armonk, N.Y., USA. Continuous data were expressed as mean +/- standard deviation (SD) and as frequencies and percentages for categorical variables.

\section{RESULTS}

A total of 532 children visited the 2-day eye health camp. Among them, 289 were male and 243 were female children. The total male to female ratio was 1.18:1. 143 (26.87\%) children amongst them had ocular morbidities with a mean age of $9.6 \pm 5.4$ years (Table 1). Refractive error, conjunctival disorders and lid disorders were found to be the top three ocular morbidities (Table 2).

\section{Table 1: Characteristics of children with ocular morbidity ( $\mathrm{N}=143)$}

\begin{tabular}{ccc|}
\hline S.N. & Characteristics & Value \\
\hline A & Age & \\
& Mean age (years) & $9.6 \pm 5.4$ \\
\hline & Range (years) & 2 to 17 \\
\hline B & Age distribution & \\
& 2 to 4 years & $8(5.59 \%)$ \\
\hline & 4 to 6 years & $18(12.58 \%)$ \\
\hline & $>6$ years & $117(81.81 \%)$ \\
\hline C & Male: female ratio $(M=86, F=42)$ & $2.04: 1$ \\
\hline
\end{tabular}

Table 2: Pattern of ocular morbidity

\begin{tabular}{|clc|}
\hline S.N. & Ocular morbidity & $\begin{array}{c}\text { Number } \\
\text { (percentage) }\end{array}$ \\
\hline 1. & Refractive error & $43(8.08 \%)$ \\
\hline 2. & Amblyopia & $10(1.87 \%)$ \\
\hline 3. & Refractive & $8(80 \%)$ \\
\hline 4. & Ctrabismus & $2(20 \%)$ \\
\hline 5. & Lid disorders & $9(1.70 \%)$ \\
\hline 6. & Congenital Nasolacrimal duct & $13(2.44 \%)$ \\
\hline 7. & Costruction & $29(5.45 \%)$ \\
\hline 8. & Conjunctival disorders & $1(0.18 \%)$ \\
\hline 9. & Prauma & $32(6.01 \%)$ \\
\hline & Total & $5(0.93 \%)$ \\
\hline
\end{tabular}

Conjunctival disorders (6.01\%) included allergic conjunctivitis and infective conjunctivitis with allergic conjunctivitis being the most common. 
Lid disorders (5.45\%) consisted of blepharitis, chalazion, stye, congenital ptosis and eyelid foreign body. Among these, blepharitis was observed most commonly followed by chalazion.

Other morbidities were convergence insufficiency (2.44\%) amblyopia (1.8\%), strabismus (1.70\%), congenital NLD obstruction $(0.18 \%)$, corneal opacity following trauma $(0.93 \%)$ and pseudophakia with nystagmus $(0.18 \%)$.

\section{DISCUSSION}

Ocular morbidities are important because of their impact on child's development, education and future work. Since most of these morbidities are preventable or treatable, reasonable service for ocular morbidity and early age screening are effective methods to reduce this load. In the present study, out of 532 cases, only 143 (26.87\%) cases were found to have ocular morbidity. This data of ocular morbidity was comparable with a study conducted by Gupta et al. in the district Shimla India, who has reported a prevalence of $31.6 \%{ }^{8}$. However, another study conducted by Nepal et al., reported prevalence as low as $11 \%^{7}$. This variation in prevalence may be because of the fact that our study was conducted outside Kathmandu valley unlike them, where three schools of Kathmandu valley were chosen ${ }^{6}$. The risk of visual disability may be more because of lack of proper health access in places outside the valley.

Male preponderance with $61.42 \%$ was found in the present study like studies conducted at western Nepal by $\mathrm{KC}$ et al. and Tuladhar et al ${ }^{9,10}$. This may be due to gender bias behavior in our community to bring male children for examination.

The most common cause of ocular morbidity in our study was refractive error (8.08\%), which was consistent with other studies done in Nepal and India ${ }^{8,11-13}$. Refractive errors can lead to an impaired quality of life and such refractive errors can be easily diagnosed, measured and corrected to attain normal vision. Numerous studies have shown that the prevalence of uncorrected refractive error is influenced by strong socio-economic factors ${ }^{14,15}$.

Conjunctival disorders comprised $6.01 \%$ cases in our study with allergic conjunctivitis being more common than infective conjunctivitis. Reported prevalence of conjunctivitis in urban setting of Nepal is $4.3 \%$ which is somewhat consistent with our results ${ }^{16}$. Geographical location, seasonal variation and personal hygiene are the factors responsible for conjunctival diseases. Public awareness and health education in the community regarding sanitation and maintaining hygiene may reduce this number ${ }^{17,18}$.

In various studies done in Nepal, prevalence of lid disorders reported was from $0.8 \%$ to $9.6 \%{ }^{16,19}$. In our study, it is $5.4 \%$ with blepharitis being most common. Other lid disorders included congenital ptosis, stye, chalazion and foreign body in lid with chalazion being 2nd most common lid morbidity. Poor eye hygiene of the children and outdoor activity are mainly responsible for eyelid disorders ${ }^{10}$. In present study, squint was seen in $1.70 \%$ of patients, which is similar to prevalence of other studies. ${ }^{5,8}$ However in the study done at Tanzania, the prevalence of squint was found to be only $0.5 \% .^{18}$ Convergence Insufficiency accounted for $2.44 \%$ of cases in our study which is somewhat consistent with the study done by Shrestha et al $(3.4 \%)^{16}$.

Various studies done in Nepal have reported prevalence of amblyopia between $0.13 \%$ and $2 \%{ }^{16,19}$. In our study also amblyopia accounted for $1.8 \%$. Amblyopia is a major ocular morbidity, consequences of which can lead to permanent visual impairment. Effective mean of management was initiated for the detected cases.

Other morbidities encountered were corneal opacity following ocular trauma in 5 cases $(0.93 \%)$, congenital NLD obstruction in 1 case $(0.18 \%)$ and pseudophakia with nystagmus in 1 case $(0.18 \%)$.

\section{CONCLUSION}

Our study showed that refractive error was the most common ocular morbidity followed by conjunctival disorders and eyelid disorders respectively. Poor vision in childhood because of refractive error and amblyopia affects performance in daily activities in school or at work and has negative influence in the future of children. Early detection and management can reduce disease progression and prevent visual disability. Health education and good ocular hygiene also carries utmost importance for the prevention of childhood eye diseases. This study reported the pattern of pediatric ocular morbidity in western mountainous region of Nepal, which we believe can be used for decreasing the burden of visual impairment and health camps like these can be an effective method for early identification of ocular diseases. Regular eye health programmes among schoolgoing children aids in early diagnosis and is necessary to alleviate the problem and reduce its consequences. School screening programmes seem to be appropriate to reduce ocular morbidity in schoolchildren in countries like Nepal. 


\section{REFERENCES}

1. Davidson S, Quinn GE. The impact of pediatric vision disorders in adulthood. Pediatrics. 2011;127(2):3349. [DOI | PubMed]

2. World Health Organization. Preventing blindness in children: report of WHO/IAPB scientific meeting. Programme for the Prevention of Blindness and Deafness, and International Agency for Prevention of Blindness. Geneva: WHO, 2000 (WHO/PBL/00.77)

3. World Health Organization. Programme for the Prevention of Blindness and Deafness. (2000). Global initiative for the elimination of avoidable blindness. World Health Organization.

4. Beck, RW. Clinical research in pediatric ophthalmology: the Pediatric Eye Disease Investigator Group. Curr Opin Ophthalmol 2002;13(5):337-40

5. Gupta P, Gupta V. Ocular morbidities in pediatric outpatient population at a tertiary care ophthalmic centre: A descriptive study. Int J Contemp Pediatr. 2018;5(4):1195. [DOI]

6. Nepal BP, Koirala S, Adhikary S, Sharma AK. Ocular morbidity in schoolchildren in Kathmandu. $\mathrm{Br} \mathrm{J}$ Ophthalmol. 2003;87:531-4. [DOI]

7. Adhikari S, Shrestha MK, Adhikari K, Maharjan N, Shrestha UD. Factors associated with childhood ocular morbidity and blindness in three ecological regions of Nepal: Nepal pediatric ocular disease study. BMC Ophthalmol. 2014;14:125. [DOI | PubMed]

8. Gupta M, Gupta BP, Chauhan A, Bhardwaj A. Ocular morbidity prevalence among school children in Shimla, Himachal, North India. Indian J Ophthalmol. 2009;57:133-8. [DOI | PubMed]

9. Rai Salma KC, Hari T, Malla BA, Kabindra B. Clinical profile of pediatric ocular morbidity in a tertiary eye care centre in western region of Nepal. Ann Pediatr Child Health. 2015;3(5):1070. [Full Text]

10. Tuladhar S, Gurung J, Poudel B, Subedi N. Pattern of ocular morbidity in pediatrics age group in a tertiary centre in western Nepal. Journal of Gandaki Medical College-Nepal. 2019;12(02):86-9. [DOI]

11. Sherpa D, Pant CR, Joshi ND. Ocular morbidity among primary school children of Dhulikhel Nepal. Nepal J Ophthalmol. 2011 Jul-Dec;3(2):172-6. [DOI]

12. Singh V, Malik KP, Malik VK, Jain K. Prevalence of ocular morbidity in school going children in West Uttar Pradesh. Indian J Ophthalmol. 2017;65:500-8. [DOI]

13. Gupta M, Gupta BP, Chauhan A, Bhardwaj A. Ocular morbidity prevalence among school children in Shimla, Himachal, North India. Indian J Ophthalmol. 2009;57:133-8. [DOI]

14. Naidoo KS, Jaggernath J. Uncorrected refractive errors. Indian J Ophthalmol. 2012;60(5):432-7. [DOI]

15. Bourne RR, Dineen BP, Huq DM, Ali SM, Johnson GJ. Correction of refractive error in the adult population of Bangladesh: meeting the unmet need. Invest Ophthalmol Vis Sci. 2004;45(2):410-7. [DOI|PubMed]

16. Shrestha RK, Shrestha GS. Ocular morbidity among children of government schools of Kathmandu valley: A follow-up series. Clin Ophthalmol. 2018;12:1645-2. [DOI]

17. Pant M, Shrestha GS, Joshi N. Ocular morbidity among street children in Kathmandu valley. Ophthalmic Epidemiol. 2014 Dec;21(6):356-61. [DOI]

18. Wedner SH, Ross DA, Balira R, Kaji L, Foster A. Prevalence of eye diseases in primary school children in a rural area of Tanzania. Br J Ophthalmol. 2000;84:1291-7. [DOI | PubMed]

19. Shrestha RK, Joshi MR, Ghising R, Rizyal A. Ocular morbidity among children attending government and private schools of Kathmandu valley. JNMA J Nepal Med Assoc. 2011 Oct-Dec;51(184):182-8. [DOI] 